\title{
ANALISIS USAHATANI TALAS SATOIMO \\ (Colocasia esculenta var. antiqourum) \\ (Studi Kasus : di Desa Suka Sari Kecamatan Kabawetan Kabupaten Kepahiang) \\ A FARMING ANALYSIS OF SATOIMO TARO (Colocasia esculenta var. antiqourum) (Case Studies : at Sukasari Village Kabawetan Subdistrict Kepahiang District)

\author{
Dhanty Dwika Amelia, Yossie Yumiati \\ Program Studi Agribisnis, Fakultas Pertanian, Universitas Dehasen Bengkulu
}

\begin{abstract}
ABSTRAK
Penelitian ini bertujuan untuk menganalisis sistem pengolahan, menganalisis besar produksi dan produktivitas, menganalisis besar pendapatan bersih, dan menganalisis tinjauan analisa ekonomi dari usahatani komoditi talas satoimo di Desa Suka Sari Kecamatan Kabawetan Kabupaten Kepahiang Provinsi Bengkulu. Metode penelitian yang dilakukan meliputi pengambilan sampel dengan menggunakan metode sensus, pengumpulan data diambil dari data sekunder dan data primer, analisis data menggunakan rumus $\boldsymbol{\pi}=$ TR-TC (Pendapatan bersih), R/C Ratio untuk mengukur kelayakan usahatani secara ekonomis. Sistem pengolahan usahatani talas satoimo yang dilakukan di daerah penelitian berupa pengolahan lahan, penanaman, pemupukan, dan pembumbunan masih tergolong sederhana, belum sesuai dengan anjuran literatur (menurut Hodijah, 2009). Besaran rata-rata produksi usahatani talas satoimo sebesar $3.265 \mathrm{~kg}$ dan produktivitas sebesar $14.446 \mathrm{~kg} / \mathrm{ha}$ masih rendah dibandingkan literatur (Penelitian SEAMEO BIOTROP Bogor Jawa Barat). Total pendapatan bersih usahatani talas satoimo selama satu kali musim tanam sebesar Rp127.319.464,-. Analisis $\mathrm{R} / \mathrm{C}$ ratio usahatani talas satoimo sebesar 2,07 sehingga usahatani yang dilakukan secara ekonomi layak untuk diusahakan $(\mathrm{R} / \mathrm{C} \geq 1)$.
\end{abstract}

Kata Kunci : Talas Satoimo, Pengolahan lahan, Produksi dan Produktivitas, Pendapatan Bersih, analisis $\mathrm{R} / \mathrm{C}$ ratio

\section{ABSTRACT}

This study aimed to analyze the system of processing, large production and productivity, substancial net income, and economic analysis review of satoimo taro farm commodities in Sukasari village Kabawetan subdistrict Kepahiang District Bengkulu Province. The research method involves taking sample by using census method, data collection taken from secondary and primary data, data analysis using the formula $\quad \pi=T R-T C$ (net income), $R / C$ Ratio to measure the feasibility of farming economically. The system of processing satoimo taro farming carried out in the area of research in the form of land preparation, planting, fertilizing, and landfill that still relatively modest yet as recommended by the literature (according to Hodijah, 2009). The average production sataimo taro farm amounted to 3,265 $\mathrm{kg}$ satoimo and productivity of $14.446 \mathrm{~kg} / \mathrm{ha}$ is still low compared to the literature (SEAMEO BIOTROP Research Bogor West Java). Total net income satoimo taro farm during one growing season is Rp127.319.464, -. Analysis of $R / C$ ratio is 2.07 satoimo taro farm therefore the farming is economically feasible to be developed $(R / C \geq 1)$.

Keywords: Satoimo Taro, Land management, Production and Productivity, Net Income, analysis of $R / C$ ratio 


\section{PENDAHULUAN}

Sektor pertanian memiliki peranan penting dalam pertumbuhan dan ketahanan ekonomi nasional. Menurut Karo-karo (2010) selain sebagai sektor yang mampu menyediakan pangan bagi penduduk Indonesia, pertanian juga mampu menyerap 46,5 persen dari total angkatan kerja di Indonesia, dan mampu memberikan kontribusi sebesar 14,7 persen bagi GNP.

Pembangunan pertanian dihadapkan kepada kondisi lingkungan yang strategis yang terus berkembang secara dinamis dan menjurus kepada liberalisasi perdagangan internasional, untuk memanfaatkan peluang yang ada, maka pembangunan pertanian harus lebih difokuskan kepada komoditi-komoditi unggulan yang dapat bersaing di pasar domestik maupun pasar internasional.

Kondisi ini menjadi dasar yang kuat bagi pemerintah untuk mempercepat laju pembangunan pertanian di Indonesia secara lebih modern dengan tujuan untuk memantapkan swasembada pangan sebagai dasar utama untuk menjaga stabilitas nasional (Daniel, 2002).

Salah satu komoditi yang saat ini memiliki prospek yang cukup tinggi, dimana permintaan pasar internasional meningkat terutama di Jepang yaitu komoditi talas satoimo (Colocasia esculensta var. antiquorum). Komoditi talas satoimo (Colocasia esculensta var. antiquorum) tergolong ke dalam suku talas-talasan atau Araceae yang mudah dikembangbiakkan dan memiliki tingkat produktivitas yang cukup tinggi.

Tingginya permintaan komoditi talas satoimo (Colocasia esculensta var. antiquorum) dari Jepang membuka peluang budidaya usahatani komoditi talas satoimo (Colocasia esculensta var. antiquorum) yang semakin lebar. Untuk mencukupi kebutuhan tersebut, pemerintah Jepang menawarkan proyek kerjasama budidaya usahatani komoditi talas satoimo (Colocasia esculensta var. antiquorum) kepada pemerintahan Kabupaten Bogor pada tahun 2006 dan dicoba oleh kelompok tani Paseban di Megamendung dan kelompok tani Kaliwurang Kalimuncar di Cisarua Bogor (Hodijah. S, 2009).

Potensi lahan yang cocok untuk berusahatani talas satoimo (Colocasia esculensta var. antiquorum) di Provinsi Bengkulu berada di Kabupaten Kepahiang. Usahatani komoditi talas satoimo (Colocasia esculensta var. antiquorum) mulai diperkenalkan untuk dibudidayakan sejak tahun 2011 lalu, hal ini juga didukung oleh Pemerintah Daerah Kabupaten Kepahiang dengan tujuan untuk dapat memenuhi kebutuhan pasar 
ekspor dunia guna mencukupi kebutuhan komoditi talas satoimo (Colocasia esculensta var. antiquorum) di Jepang dan akan meningkatkan kesejahteraan masyarakat khususnya petani di kabupaten Kepahiang. Oleh karena itu peneliti tertarik untuk menganalisis usahatani yang dilakukan oleh petani komoditi talas satoimo (Colocasia esculensta var. antiquorum) di Desa Suka Sari Kecamatan Kabawetan Kabupaten Kepahiang tersebut, dengan melihat potensi lahan yang ideal guna berusahatani talas satoimo.

Usahatani merupakan ilmu terapan yang membahas atau mempelajari bagaimana membuat atau menggunakan sumber daya secara efisien pada suatu usaha pertanian. Usahatani juga sebagai organisasi dari alam, kerja dan modal yang ditujukan kepada produksi di lapangan pertanian (Pindrik, 2003). Menurut Makeham, J.P (1991) usahatani merupakan himpunan sumber-sumber alam yang terdapat di tempat itu yang digunakan untuk produksi pertanian seperti tanah yang subur, air, perbaikan yang dilakukan, sinar matahari, bangunan-bangunan yang didirikan di atas tanah tersebut. Hal ini dibenarkan oleh Mubyarto (1989) bahwa usahatani sebagai suatu tempat atau bagian permukaan bumi dimana pertanian diselenggarakan oleh seorang petani tertentu sebagai pemilik lahan ataupun manager yang digaji.

Tujuan dari penelitian ini adalah untuk menganalisis sistem pengolahan usahatani, besar produksi dan produktivitas usahatani,

besar pendapatan dan tinjauan analisa ekonomi dari usahatani komoditi talas satoimo (Colocasia esculensta var. antiquorum) di Desa Suka Sari Kecamatan Kabawetan Kabupaten Kapahiang.

\section{METODOLOGI PENELITIAN}

\section{Waktu dan Lokasi Penelitian}

Penelitian ini telah dilakukan di Desa Suka Sari Kecamatan Kabawetan Kabupaten Kepahiang Propinsi Bengkulu pada bulan Oktober 2014 - Januari 2015. Daerah penelitian ditentukan secara pusposive yaitu Desa Suka Sari Kecamatan Kabawetan Kabupaten Kepahiang. Alasan penentuan dan penetapan daerah tersebut sebagai daerah penelitian, karena Desa Suka Sari merupakan salah satu sentra produksi usahatani komoditi talas satoimo di Kabupaten Kepahiang Provinsi Bengkulu yang memiliki luas lahan terbesar yang ditanami talas satoimo, yaitu 5 hektar dan hasil produksi dan produktivitasnya yang terbesar. 
Tabel 1. Luas Lahan, Produksi dan Produktivitas Usahatani Komoditi Talas Satoimo Kabupaten Kepahiang Provinsi Bengkulu Tahun 2013.

\begin{tabular}{llcccc}
\hline No & Nama Desa & $\begin{array}{c}\text { Ketinggian } \\
(\mathrm{mdpl})\end{array}$ & $\begin{array}{c}\text { Luas } \\
\text { Lahan } \\
(\mathrm{Ha})\end{array}$ & $\begin{array}{c}\text { Produksi } \\
(\mathrm{kg})\end{array}$ & $\begin{array}{c}\text { Produktivitas } \\
(\mathrm{kg} / \mathrm{Ha})\end{array}$ \\
\hline 1. & Tebat Monok & 520 & 1 & 12.400 & 12.400 \\
2. & Bumi Sari & 660 & 0,5 & 6.650 & 13.300 \\
3. & Pematang Donok & 780 & 0,5 & 7.300 & 14.600 \\
4. & Suka Sari & $\mathbf{1 . 1 0 0}$ & $\mathbf{5}$ & $\mathbf{7 4 . 5 0 0}$ & $\mathbf{1 4 . 9 0 0}$ \\
\hline
\end{tabular}

Sumber : Dinas Pertanian Kabupaten Kepahiang, 2013

\section{Metode Pengambilan Sampel}

Petani yang menjadi responden merupakan petani yang berusahatani komoditi talas satoimo di Desa Suka Sari kecamatan Kabawetan Kabupaten Kepahiang pada periode tanam tahun 2013. Teknik penentuan responden secara sensus dengan jumlah responden sebanyak 25 KK. Menurut Sukandarrumidi (2006) metode sensus adalah teknik pengambilan sampel dengan anggota sampel yang diambil secara keseluruhan karena di daerah penelitian memiliki sampel yang sedikit.

\section{Metode Pengumpulan Data}

Data yang dikumpulkan dalam penelitian ini terdiri dari data primer dan data sekunder. Data primer diperoleh dari hasil wawancara langsung dengan petani yang berusahatani komoditi talas satoimo di Desa Suka Sari Kecamatan Kabawetan
Kabupaten Kepahiang melalui survei kuisioner yang telah dipersiapkan terlebih dahulu. Data sekunder diperoleh melalui instansi yang terkait seperti Dinas Pertanian dan Tanaman Pangan Kabupaten Kepahiang, Koordinator Penyuluh usahatani Talas Satoimo Kecamatan Kabawetan, website yang terkait, jurnal, dan buku.

\section{Metode Analisis Data}

Untuk mengetahui sistem pengolahan usahatani talas satoimo di Desa Suka Sari Kecamatan Kabawetan Kabupaten Kepahiang akan dianalisis secara deskriptif yaitu dengan membandingkan sistem pengolahan usahatani komoditi talas satoimo menurut literatur. Untuk mengetahui tingkat produksi dan produktivitas usahatani talas satoimo di Desa Suka Sari Kecamatan Kabawetan Kabupaten Kepahiang akan dianalisis 
secara deskriptif dengan membandingkan produksi dan produktivitas yang dihasilkan di daerah penelitian menurut anjuran literatur. Untuk mengetahui besarnya pendapatan petani yang berusahatani talas satoimo di Desa Suka Sari Kecamatan Kabawetan Kabupaten Kepahiang dilakukan analisis secara tabulasi sederhana, dengan fungsi sebagai berikut :

$\boldsymbol{\pi}=\mathbf{T R}-\mathbf{T C}($ Soekartawi, 2006)

Dimana :

$\pi($ Pendapatan $)=$ Pendapatan bersih petani $(\mathrm{Rp} / \mathrm{Ut})$

TR $($ Total Revenue $)=$ Total penerimaan $(\mathrm{Rp} / \mathrm{Ut})$

TC $($ Total Cost $)=$ Total Biaya $(\mathrm{Rp} / \mathrm{Ut})$

Untuk mengetahui layak atau tidaknya usahatani talas satoimo di Desa Suka Sari Kecamatan Kabawetan Kabupaten Kepahiang adalah dengan menggunakan analisis Return Cost Ratio (R/C Ratio).

1. Biaya Produksi dihitung dengan rumus sebagai berikut :

$$
\mathbf{C}=\mathbf{F C}+\mathbf{V C}
$$

Dimana :

$\mathrm{C}($ Cost $)=$ Biaya Total $(\mathrm{Rp})$

VC $($ Variabel Cost $)=$ Biaya Variabel $(\mathrm{Rp} / \mathrm{Ut})$

$\mathrm{FC}($ Fixed Cost $) \quad=$ Biaya Tetap (Rp/Ut)

2. Penerimaan adalah produksi dikali harga jual dengan rumus sebagai berikut :

$$
\mathbf{R}=\mathbf{P y} \cdot \mathbf{Y}
$$

Dimana :

$\mathrm{R}$ (Revenue) = Penerimaan

Py (Price) = Harga Jual

$\mathrm{Y}($ Product $) \quad=$ Produksi $(\mathrm{Kg} / \mathrm{Ut})$

Dengan kriteria sebagai berikut :

\section{$\mathbf{R} / \mathbf{C}$}

Jika $\mathrm{R} / \mathrm{C} \geq 1$, maka usahatani komoditi talas satoimo secara ekonomis layak diusahakan

Jika $\mathrm{R} / \mathrm{C}<1$, maka usahatani komoditi talas satoimo secara ekonomis tidak layak diusahakan.

\section{HASIL DAN PEMBAHASAN}

\section{Keadaan Umum Petani Sampel}

Usahatani Talas Satoimo di Daerah

\section{Penelitian}

Tabel 2 menunjukkan bahwa rataan luas lahan yang dimiliki untuk berusahatani talas satoimo di Desa Suka Sari Kecamatan Kabawetan sebesar 0,226 hektar, hal ini diasumsikan bahwa luas lahan yang diusahakan masing-masing petani sampel masih kecil, hal ini dikarenakan pembudidayaan talas satoimo yang masih bersifat uji coba yang baru diperkenalkan oleh pemerintah kepada petani yaitu tahun 2013 dimana usahatani yang dilakukan masih memasuki tahap uji adaptasi lahan dan iklim. 
Tabel 2. Tabel Karakteristik Petani Sampel Desa Suka Sari Kecamatan Kabawetan Kabupaten Kepahiang

\begin{tabular}{llcc}
\hline No & Uraian & Range & Rata-rata \\
\hline 1 & Luas lahan (Ha) & $0,1-0,75$ & 0,226 \\
2 & Umur (Tahun) & $28-61$ & 39,24 \\
3 & Tingkat pendidikan (Tahun) & $6-9$ & 7,68 \\
4 & Jumlah tanggungan (Jiwa) & $2-5$ & 3,56 \\
5 & Pengalaman berusahatani (Tahun) & $0-0,5$ & 0,5 \\
\hline
\end{tabular}

Berdasarkan Tabel 2 juga diketahui bahwa umur rata-rata petani sampel usahatani talas satoimo masih dalam usia produktif yaitu 39,24 tahun. Tingkat pendidikan petani sampel talas satoimo dengan range 6-9 tahun, yaitu dengan rata-rata 7,68 tahun, hal ini menunjukkan bahwa wawasan berpikir petani masih belum begitu baik yaitu setara SD/SMP, sehingga pertanian yang dilakukanpun masih bersifat sederhana dan masih sangat perlu campur tangan penyuluh dalam menerapkan teknologi untuk kegiatan usahatani talas satoimo.

Rata-rata jumlah tanggungan petani sampel di Desa Suka Sari adalah 3,56 jiwa, hal ini menunjukkan jumlah tanggungan per petani tidak terlalu besar apabila dilihat dari rataan jumlah tanggungan, dimana pendapatan yang diperoleh oleh petani bukan hanya berasal dari komoditi talas satoimo melainkan berasal dari usahatani komoditi lain dari lahan yang mereka miliki, sehingga dapat memenuhi kebutuhan rumah tangga petani. Rataan pengalaman berusahatani talas satoimo petani sampel di Desa Suka Sari Kecamatan Kabawetan adalah 0,5 tahun, hal ini dikarenakan pada desa tersebut hanya dilakukan satu kali percobaan budidaya talas satoimo yaitu satu kali musim tanam (5-6 bulan) dimana usahatani talas satoimo mulai diperkenalkan oleh pemerintah kepada petani di daerah penelitian tersebut adalah pada tahun 2013. Dalam rata-rata 0,5 tahun usahatani yang dilakukan merupakan usahatani yang baru dilaksanakan. 


\section{Sistem Pengolahan Usahatani di Desa Suka Sari}

Tabel 3. Budidaya Usahatani Talas Satoimo Menurut Anjuran dan Fakta di Lapangan

\begin{tabular}{|c|c|c|c|c|}
\hline No & $\begin{array}{c}\text { Jenis } \\
\text { Kegiatan }\end{array}$ & Anjuran & Keadaan lapangan & Keterangan \\
\hline 1 & $\begin{array}{l}\text { Pengolahan } \\
\text { lahan }\end{array}$ & $\begin{array}{l}\text { - Tanah dicangkul, } \\
\text { digemburkan dan } \\
\text { dibersihkan dari gulma } \\
\text { - Dibuat bedengan } \\
\text { dengan lebar : } 60 \mathrm{~cm} \text {, } \\
\text { panjang : } 120 \mathrm{~cm} \text {, tinggi : } \\
15 \mathrm{~cm}, \text { jarak antar } \\
\text { bedengan : } 40 \mathrm{~cm} \text {. } \\
\text { - Buat lubang tanam } \\
\text { ukuran } 40 \mathrm{x} 40 \mathrm{~cm} \text {, } \\
\text { diameter } 25 \quad \mathrm{~cm} \text {, } \\
\text { kedalaman } 15 \mathrm{~cm} .\end{array}$ & $\begin{array}{l}\text { - Tanah dicangkul, } \\
\text { digemburkan dan } \\
\text { dibersihkan dari gulma } \\
\text {-Dibuat bedengan dengan } \\
\text { lebar } 20 \mathrm{~cm} \text {, tinggi } 10-15 \\
\mathrm{~cm} \\
\text { - Buat lubang tanam } 20 \times 40 \\
\text { cm kedalaman } 20 \mathrm{~cm}\end{array}$ & Belum sesuai \\
\hline 2 & Penanaman & $\begin{array}{l}\text { Umbi dicelup larutan } \\
\text { banlete } 2 \mathrm{gr} / \mathrm{l} \text { air sebelum } \\
\text { ditanam, ditanam sedalam } \\
10 \mathrm{~cm} \text {, siram setelah } \\
\text { tanam. }\end{array}$ & $\begin{array}{l}\text { Secara langsung di atas } \\
\text { bedengan }\end{array}$ & Belum sesuai \\
\hline 3 & Pembubunan & $\begin{array}{l}\text { Dilakukan } \\
\text { bertahap secara } \\
\text { sejak fase berumbi } \\
\text { dengan tinggi } 5-10 \mathrm{~cm} \\
\text { dari pangkal batang. }\end{array}$ & $\begin{array}{l}1 \text { kali pembubunan pada usia } \\
2-3 \text { bulan }\end{array}$ & Belum sesuai \\
\hline 4 & Pemupukan & $\begin{array}{l}- \text { Pupuk organik } \\
400-500 \mathrm{~g} / \text { tanaman. } \\
-\quad 24 \text { hari setelah } \\
\text { tanam diberi } 5 \mathrm{~g} / \text { tanaman } \\
\text { pupuk NPK. } \\
-\quad 1 \text { bulan setelah } \\
\text { tanam diberi } 5 \mathrm{~g} / \text { tanaman } \\
\text { pupuk NPK }\end{array}$ & $\begin{array}{l}\text {-Diberi pupuk organik saat } \\
\text { pengolahan lahan sebanyak } \\
0,5 \mathrm{~kg} / \mathrm{tanaman} \\
\text {-Diberi pupuk kedua pada } \\
\text { usia } 2 \text { atau } 3 \text { bulan } \\
\text { sebanyak } 0,33 \mathrm{~kg} / \text { tanaman }\end{array}$ & Belum sesuai \\
\hline 5 & Penyulaman & $\begin{array}{l}\text { Dilakukan } 2 \text { minggu } \\
\text { setelah tanam }\end{array}$ & $\begin{array}{l}\text { Tidak dilakukan, karena bibit } \\
\text { yang diberikan pemerintah } \\
\text { terbatas jumlahnya. }\end{array}$ & Belum sesuai \\
\hline 6 & Pemanenan & \begin{tabular}{lll}
- & Usia panen & $5-6$ \\
bulan & & \\
- & Dilakukan & saat \\
hujan & & \\
- & Dicabut & tidak \\
\multicolumn{2}{c}{ menggunakan cangkul. }
\end{tabular} & $\begin{array}{l}\text {-Usia panen } 5-6 \text { bulan } \\
\text {-Dilakukan saat hujan } \\
\text {-Dicabut tidak menggunakan } \\
\text { cangkul }\end{array}$ & Sesuai \\
\hline
\end{tabular}

Sumber : Hodijah, S, 2009 dan Data Primer, 2015 
Produksi dan Produktivitas Usahatani Talas Satoimo Di Desa Suka Sari

Tabel 4. Produksi dan Produktivitas Usahatani Talas Satoimo Selama Musim Tanam (6 bulan) Di Desa Suka Sari.

\begin{tabular}{ccc}
\hline Uraian & Jumlah & Rata-rata \\
\hline Luas lahan $(\mathrm{Ha})$ & 5,65 & 0,23 \\
Produksi $(\mathrm{Kg}):$ & 81.622 & \\
a. Per petani $\quad(\mathrm{Kg})$ & & 3.265 \\
b. Per Tanaman (Kg) & & 3,40 \\
Produktivitas (Kg/Ha) & 361.640 & 14.466 \\
\hline
\end{tabular}

Tabel 4 menunjukkan bahwa rata-rata luas lahan usahatani talas satoimo di Desa Suka Sari Kecamatan Kabawetan Kabupaten Kepahiang adalah 0,23 hektar dengan produksi sebesar $81.622 \mathrm{~kg}$ atau rata-rata $3.265 \mathrm{~kg}$ per petani dan produktivitasnya sebesar $361.640 \mathrm{Kg} / \mathrm{Ha}$ atau rata-rata $14.466 \mathrm{Kg} / \mathrm{Ha}$ per petani, dengan produksi 3,40 $\mathrm{kg}$ per tanaman. Menurut anjuran dari Balai Penelitian SEAMEO BIOTROP Bogor Jawa Barat bahwa dalam 1 hektar luas lahan yang ditanami sebanyak 25.000 bibit dengan rata-rata produksi per tanaman adalah 5 kg sehingga menghasilkan produktivitas sebanyak 125.000 Kg/Ha (Anonim, 2014).

\section{Penerimaan Usahatani Talas Satoimo di Daerah Penelitian}

Dari Tabel 5 diketahui bahwa rataan penerimaan per petani adalah sebesar Rp9.794.640,- dan rata-rata penerimaan per hektarnya sebesar Rp43.339.115,04,dengan total penerimaan dalam satu musim tanam (6 bulan) adalah Rp244.866.000,- pada daerah penelitian. Dari uraian di atas dapat diketahui bahwa dalam satu musim tanam (6 bulan), usahatani talas satoimo sudah dapat menghasilkan penerimaan sebesar Rp244.866.000,- meskipun usahatani talas satoimo yang dilakukan di daerah tersebut baru dilaksanakan selama satu kali musim tanam (6 bulan) dimana usahatani yang dilakukan masih bersifat uji adaptasi lahan dan iklim, sehingga penerimaan usahatani talas satoimo di Desa Suka Sari dapat ditingkatkan seiring dengan bertambahnya pengalaman dan pengetahuan dalam berusahatani talas satoimo. 
Pendapatan Bersih Usahatani Talas

\section{Satoimo di Daerah Penelitian}

Dari Tabel 6 diketahui bahwa rata-rata pendapatan bersih yang diperoleh per petani adalah sebesar Rp5.092.778,67,dan rata-rata pendapatan bersih per hektarnya adalah sebesar Rp22.534.418,88,-. Pendapatan bersih dalam usahatani talas satoimo dihasilkan selama satu kali musim tanam (6 bulan). Dalam hal ini pendapatan bersih usahatani yang dihasilkan oleh para petani talas satoimo di Desa Suka Sari sudah sebesar Rp5.092.778,67,- walaupun usahatani talas satoimo yang dilakukan hanya satu kali musim tanam (6 bulan) dalam satu tahun. Hal ini dikarenakan program percobaan budidaya yang dilakukan di
Desa Suka Sari Kecamatan Kabawetan Kabupaten Kepahiang baru dimulai pada tahun 2013 dan hanya dilakukan satu kali masa panen (6 bulan).

\begin{abstract}
Analisis R/C Usahatani Talas Satoimo
Berdasarkan Tabel 7 di atas bahwa nilai $\mathrm{R} / \mathrm{C}$ usahatani talas satoimo di daerah penelitian adalah sebesar 2,07 sehingga usahatani talas satoimo yang dilakukan di Desa Suka Sari Kecamatan Kabawetan Kabupaten Kepahiang secara ekonomis layak untuk diusahakan. Dari uraian tersebut maka hipotesis 4 diterima, bahwa usahtani talas satoimo secara ekonomi layak untuk diusahakan di Desa Suka Sari tersebut.
\end{abstract}

Tabel 5. Rata-Rata Penerimaan Usahatani Talas Satoimo Selama Musim Tanam (6 bulan)

\begin{tabular}{lccc}
\hline \multirow{2}{*}{ Uraian } & \multicolumn{2}{c}{ Rata-rata } & \multirow{2}{*}{ Total } \\
& Per Petani & Per Hektar & $(\mathrm{Rp} / \mathrm{UT})$ \\
& $(\mathrm{Rp})$ & $(\mathrm{Rp})$ & \\
\hline Penerimaan & 9.794 .640 & $43.339 .115,04$ & 244.866 .000 \\
Biaya & 4.701 .861 & $20.804 .696,17$ & 117.546 .533 \\
\hline
\end{tabular}


Tabel 6. Rata-Rata Pendapatan Bersih Usahatani Talas Satoimo Selama Musim Tanam (6 Bulan) di Desa Suka Sari

\begin{tabular}{lc}
\hline Pendapatan Bersih & Rata-rata (Rp) \\
\hline Per petani & $5.092 .778,67$ \\
Per hektar & $22.534 .418,88$ \\
\hline
\end{tabular}

Tabel 7. Rata-rata Nilai R/C Usahatani Talas Satoimo di Desa Suka Sari

\begin{tabular}{ccc}
\hline Desa & R/C & Keterangan \\
\hline Suka Sari & 2,07 & Layak \\
\hline
\end{tabular}

\section{SIMPULAN}

Sistem pengolahan usahatani talas satoimo di Desa Suka Sari Kecamatan Kabawetan Kabupaten Kepahiang berupa pengolahan lahan, penanaman, pemupukan, dan pembubunan masih tergolong sederhana dan tidak sesuai dengan anjuran Hodijah, S (2009). Produksi dan produktivitas usahatani talas satoimo di Desa Suka Sari sebesar $81.622 \mathrm{~kg}$ dan $361.640 \mathrm{~kg} / \mathrm{ha}$, dengan rata-rata produksi dan produktivitas per petani sebesar $3.265 \mathrm{~kg}$ dan $14.446 \mathrm{~kg} / \mathrm{ha}$. Dan memiliki produksi dan produktivitas per hektarnya sebesar $14.446,37 \mathrm{~kg}$ dan $64.007,08 \mathrm{~kg} / \mathrm{ha}$ dengan rata-rata $3,40 \mathrm{~kg}$ per tanaman. Produksi dan produktivitas tersebut masih lebih rendah dari lembaga penelitian SEAMEO BIOTROP Bogor Jawa Barat. (125.000 kg/ha). Total pendapatan bersih dalam satu musim tanam (6 bulan) di Desa Suka Sari yaitu sebesar Rp127.319.464,dengan rata-rata per petani adalah sebesar Rp5.092.778,67,- dan ratarata per hektar sebesar Rp22.534.418,88,- . Dari pendapatan bersih yang dihasilkan sudah dapat diperoleh petani walaupun usahatani yang dilakukan masih baru yaitu hanya satu kali musim tanam

(6 bulan). Analisis R/C ratio pada usahatani talas satoimo menunjukkan angka 2,07 sehingga layak secara ekonomis untuk diusahakan di desa tersebut.

\section{DAFTAR PUSTAKA}

Anonim. 2014. Talas jepang (Satoimo). Service Laboratory SEAMEO BIOTROP. Bogor. Jawa barat. 
Daniel, Mochar. 2002. Pengantar Ekonomi Pertanian. Bumi Aksara. Jakarta.

Dinas Pertanian dan Ketahanan Pangan. 2014. Prospek

Pengembangan Talas Jepang di Kabupaten Kepahiang. Agro Inovasi. Balitkabi. Bengkulu.

2013. Data Rencana Pelepasan Variates Talas Satoimo. Kepahiang. Bengkulu.

Hodijah, Saeful. 2009. Teknologi Budidaya Talas Saici. Bogor. [online] tersedia : http://cybex.deptan.go.id (diakses pada tanggal 11 September 2014).

Karo-karo, Feryanto W. 2010. Pupuk dan Subsidi : Kebijakan yang Tidak Tepat Sasaran. [online] tersedia : http://feryanto.wk.staff.ip b.ac.id (diakses tanggal 11 September 2014)

Makeham, J. P. 1991. The Economics of Tropical

Farm
Management

(terjemahan).

LP3ES. Jakarta.

Mubyarto. 1984. Pengantar Ekonomi Pertanian. LP3ES. Jakarta.

Pidrik, 2003. Analisis Produksi, Pendapatan dan Pemasaran Usahatani Singkong di Desa Gunung Agung Kecamatan Sekampung Upik Lmpung Timur. Skripsi. Sosial Ekonomi Pertanian, Fakultas Pertanian, Universitas Bengkulu. (tidak dipublikasikan)

Soekartawi,2006. Ilmu Usahatani dan Penelitian untuk Pengembangan Petani Kecil. Pers. Jakarta.

Sukandarrumidi. 2006. Metodologi Penelitian : Petunjuk Praktis Untuk Peneliti Pemula. Gajah Mada University Press. Yogyakarta. 